\title{
Enraizamiento de mora (Rubus adenotrichus) en medio líquido en el sistema de inmersión temporal y su aclimatación en invernadero
}

\author{
Dora Flores Mora' \\ Randall Chacón Cerdas² \\ Vilma Jiménez Bonilla ${ }^{3}$ \\ Fabián Ortiz Sancho ${ }^{4}$
}

Fecha de recepción: 18 de mayo del 2011 Fecha de aceptación: 7 de octubre del 2011

Flores, D; Chacón, R; Jiménez, V; Ortiz, F. Enraizamiento de mora (Rubus adenotrichus) en medio líquido en el sistema de inmersión temporal y su aclimatación en invernadero. Tecnología en Marcha. Vol. 25, No 2. Abril-Junio 2012. Pág 3-9.

Ingeniera agrónoma. Escuela de Biología, Tecnológico de Costa Rica.Teléfono: 2550-9163. Correo electrónico: dflores@itcr.ac.cr

2 Ingeniero en biotecnología. Escuela de Biología, Tecnológico de Costa Rica. Teléfono: 2550-9163.

Correo electrónico: rchacon@itcr.ac.cr

3 Profesora, Escuela de Biología, Tecnológico de Costa Rica. Teléfono: 2550-9|63. Correo electrónico: vijimenez@itcr.ac.cr

4 Ingeniero en Biotecnología, empresa privada Jaguar House. Correo electrónico: fabian.ortiz@jaguarinnovation.com 


\section{Resumen}

Se presentan los resultados de una investigación cuyo objetivo fue evaluar el efecto de tres concentraciones de Ácido Indolbutírico (AIB) sobre el enraizamiento in vitro de la mora "vino sin espinas". Se utilizó un sistema de inmersión temporal automatizado para determinar la sobrevivencia de las plántulas durante la aclimatación. Se empleó un medio de cultivo líquido MS con sales al 50\%, sacarosa al 3\% y pH 5.7, suplementado con 0.125 (TI), 0.250 (T2) y 0.500 (T3=control) $\mathrm{mg} / \mathrm{L}$ de AlB.

En cada recipiente para inmersión temporal se colocaron $200 \mathrm{ml}$ de medio y 15 explantes, se programó la inmersión por 5 minutos cada 12 horas, se incubaron a $20^{\circ} \mathrm{C}$ y $16 \mathrm{~h}$ luz por ocho semanas. Se aplicó el análisis de ANDEVA y las pruebas de Tukey para evaluar la longitud del tallo, la longitud de las raíces y el número de entrenudos. Las vitroplantas se aclimataron en un sustrato compuesto de suelo, carbón vegetal y granza de arroz (3:1:1) y se determinó el porcentaje de sobrevivencia durante cuatro semanas. TI registró la mayor longitud del tallo $(6.49 \mathrm{~cm})$ y fue estadísticamente diferente a T2 y T3.T3 presentó la mayor longitud radical (4.73 $\mathrm{cm}$ ) y fue estadísticamente igual a TI y T2. Ningún tratamiento mostró diferencia estadística en el número de entrenudos (8 promedio).T2 mostró la mayor sobrevivencia de plántulas a la cuarta semana de aclimatación con un 78.6\% seguido delT3 (57.9\%) yTI (43.3\%).

Se concluyó que las plantas provenientes de T2 $(0.250 \mathrm{mg} / \mathrm{LAIB})$, las cuales presentaron una longitud promedio de tallo de aproximadamente $6 \mathrm{~cm}$ y una longitud promedio de raíz de aproximadamente $4 \mathrm{~cm}$, mostraron la mayor sobrevivencia durante la etapa de aclimatación. La investigación se realizó en el Tecnológico de Costa Rica durante el 2008.

\section{Palabras clave}

Mora, cultivo in vitro, inmersión temporal, medios líquidos, aclimatación de vitroplantas.

\section{Abstract}

The objective of this research was to evaluate the effect of three concentrations of Indol Butyric Acid (IBA) on the in vitro rooting of the "Thornless Wine" blackberry in the Temporary Immersion System and to determine its survival to acclimatization. The liquid cultivation medium consisted of MS salts at 50\%, 3\% sucrose, $\mathrm{pH}$ 5.7.The IBA concentrations of 0.125 (TI), 0.250 (T2) and 0.500 (T3=control) $\mathrm{mg} / \mathrm{L}$ were also added. In each temporary immersion container, 200 $\mathrm{ml}$ of medium and 15 explants were placed. Fiveminute immersion time was programmed every 12 hours.

The treatments were incubated at $20^{\circ} \mathrm{C}$ and 16 hours of light for 8 weeks. ANOVA and Tukey tests were applied to evaluate the length of the stem, the length of the roots, and the number of internodes. The vitroplants were acclimatized in a substrate of, vegetable charcoal, and rice peels (3:1: I); and survival was evaluated after a month. The $\mathrm{TI}$ registered the tallest stem $(6.49 \mathrm{~cm})$ and was statistically different to T2 and T3. The T3 showed the longest roots (4,73 $\mathrm{cm}$ ) and was statistically similar to $\mathrm{TI}$ and $\mathrm{T} 2$.

Treatments showed no statistical difference in the number of internodes (8 average).T2 showed $78.6 \%$ of plant survival at month, T3 $57.9 \%$, and TI $43.3 \%$. It was concluded that plants from T2 $(0.250 \mathrm{mg} / \mathrm{L}$ IBA), which showed an average length of about $6 \mathrm{~cm}$ stem and root average length of about $4 \mathrm{~cm}$, showed the highest survival during the acclimatization stage. This research was carried out in the Costa Rica Institute of Technology during the year 2008.

\section{Key words}

Blackberry, tissue culture, temporary immersion, temporary immersion containers, liquid medium, acclimatization of vitroplants. 


\section{Introducción}

En Costa Rica la mora criolla variedad "vino" (Rubus adenotrichus) es la que más se cultiva (Obando, 2003). Su disponibilidad se ha visto favorecida por la aplicación de la técnica de micropropagación, la cual les ha permitido a los agricultores obtener material vegetal para establecer plantaciones en campo. A pesar de que se cuenta con un protocolo para la micropropagación de esta especie, una de las etapas criticas es el enraizamiento de las vitroplantas, el cual se lleva a cabo tradicionalmente en medio semisólido y tarda tres meses (Flores et al., 2005), siendo necesario reducir este periodo para acelerar el proceso.

El sistema de inmersión temporal automatizado presenta ventajas comparativas en relación con el uso de los métodos tradicionales de cultivo de tejidos, ya que este sistema reduce el tiempo de respuesta de las vitroplantas debido a que absorben más rápido los nutrientes y los reguladores de crecimiento en los medios de cultivo líquidos (Alvard y Teisson, 1993). Además, este sistema permite la renovación de la atmósfera en el recipiente, lo que incide en un aumento del vigor de las vitroplantas (Aragón et al., 2006). El uso de tiempos controlados de inmersión en los medios líquidos, promueve también el control y reducción de la hiperhidricidad (Etienne y Berthouly, 2002).

Los reguladores del crecimiento en los medios de cultivo permiten direccionar la morfogénesis de los tejidos y modificar las respuestas fisiológicas en condiciones in vitro. Dentro de estos compuestos se encuentran las auxinas, cuyos efectos están relacionados con la dominancia apical y con la inducción de los procesos rizogénicos en las plantas y promueven el crecimiento por medio de los mecanismos de elongación celular (Salisbury y Ross, 1994; Sihna, 2004). Taiz y Zeiger (2006) mencionan que las células de las plantas se expanden en tres etapas: primero ocurre una absorción osmótica de agua a través de la membrana plasmática promovida por un gradiente de potencial hídrico, luego se produce la rigidez de la pared por la presión de turgencia y, por último, ocurre un aflojamiento de esta inducido por efectos bioquímicos, seguido de la expansión celular, lo que conlleva a un crecimiento de las plantas en cultivo in vitro.
El AIB se caracteriza por ser una de las auxinas sintéticas más utilizadas para promover el enraizamiento de plantas in vitro (Sinha, 2004). En estudios realizados por Wiesman y colaboradores (1989), sobre la aplicación de AIB a microestacas de frijol, se determinó que esta auxina permanece libre en los tejidos durante muy poco tiempo, por lo que se modifica bioquímicamente para promover una respuesta sostenida del enraizamiento.

La concentración de fitohormonas endógenas influye en la respuesta fisiológica promovida por reguladores exógenos ya que, dependiendo del grado de actividad bioquímica dentro de las plantas, pueden acelerar la organogénesis; lo anterior, cuando se alcanzan concentraciones sinérgicas que favorezcan el proceso celular; o bien, pueden inhibir el efecto cuando se activan mecanismos antagonistas (Salisbury y Ross, 1994).

Para el caso particular de las auxinas se conoce que la tasa de elongación es proporcional a la concentración, por lo que se esperaría una mayor elongación a mayores concentraciones de regulador; sin embargo, existen rangos de tolerancia propios para cada especie (Sinha, 2004) con la finalidad de producir vitroplantas que presenten un buen desarrollo y que posean un sistema radical óptimo que les permita ser trasladadas al invernadero para su aclimatación.

En esta etapa las plántulas requieren condiciones ambientales controladas que les permitan superar el estrés al cual son sometidas, ya que provienen de una condición semiheterótrofa inducida. Las vitroplantas generalmente carecen de una adecuada funcionalidad estomática, presentan poca diferenciación del mesófilo y la lámina foliar tiene poca protección ante la transpiración excesiva (Pospóśilová et al., 1999), por lo que durante esta etapa se aplican polisacáridos y multiminerales para que coadyuven en la activación de los procesos fisiológicos que les permita controlar la transpiración logrando mayor capacidad fotosintética autónoma.

El objetivo de esta investigación fue determinar la mejor concentración de AIB para la producción de raíces en vitroplantas de mora en recipiente para inmersión temporal, y evaluar los porcentajes de sobrevivencia durante la etapa de aclimatación en invernadero. 


\section{Metodología}

\section{Enraizamiento in vitro}

La investigación se realizó en el Centro de Investigación en Biotecnología (CIB) del Tecnológico de Costa Rica (TEC), durante el 2008. Se preparó un medio de cultivo líquido MS (Murashige y Skoog, 1962) con sales al 50\%, sacarosa al $3 \%$ y un $\mathrm{pH}$ de 5.7. Se evaluaron tres tratamientos: $0.125 \mathrm{mg} / \mathrm{L}$ ( $\mathrm{TI}$ ), $0.250 \mathrm{mg} / \mathrm{L}$ (T2) y $0.500 \mathrm{mg} / \mathrm{L}$ (T3==control) de AIB (T3: concentración de AIB reportada para enraizamiento en medio semisólido según Flores et al. (2005)). Cada tratamiento consistió de 30 ejes de $2-3 \mathrm{~cm}$ de longitud de la variedad "vino sin espinas".

La densidad de siembra empleada fue de 15 ejes por recipiente para inmersión temporal con $200 \mathrm{ml}$ de medio de cultivo. El periodo de inmersión fue de cinco minutos con una frecuencia de dos veces al día (cada 12 horas). Cada tratamiento se mantuvo en incubación a $20^{\circ} \mathrm{C}$ con un fotoperiodo de $16 \mathrm{~h}$ por ocho semanas. Los parámetros por evaluar fueron la longitud promedio de las vitroplantas, la cual se obtuvo desde la base del tallo hasta la base del ápice caulinar; el número total de entrenudos y la longitud promedio de las raíces adventicias seleccionando la más larga de cada vitroplanta.

\section{Aclimatación en invernadero}

Se procedió a aclimatar las vitroplantas provenientes de cada uno de los tratamientos de inmersión temporal en un sustrato compuesto de suelo, carbón vegetal y granza de arroz (3:1:I). Se evaluó la sobrevivencia durante cuatro semanas, monitoreando la humedad relativa y la temperatura promedio durante la mañana, el mediodía y la tarde utilizando un termohidrómetro digital. Para el manejo de las vitroplantas se aplicó el protocolo establecido por Flores y colaboradores (2005).

Durante la primera semana de aclimatación, las vitroplantas se mantuvieron en oscuridad en cajones de madera previamente desinfectados con una solución bactericida de sulfato de estreptomicina al $80 \%$ y clorhidrato de oxitetraciclina al $75 \%$ $(5.0 \mathrm{~g} / \mathrm{L})$ y el fungicida ziram al $76 \%(5.0 \mathrm{~g} / \mathrm{L})$. A los ocho días se realizó la aplicación de una fórmula foliar de polisacáridos (35\%), ácidos fúlvicos (0,1\%), aminoácidos $(0,1 \%)$, boro (2\%), nitrógeno $(6,5 \%)$ y potasio $(23 \%)(5 \mathrm{ml} / \mathrm{L})$.

Durante la segunda semana se procedió a la apertura de los cajones, lo cual condujo a un incremento de la luminosidad y una disminución de la humedad relativa. Al final de esta semana se aplicó una fórmula foliar de multiminerales NPK I I-8-6 con porcentajes menores al $1 \%$ de $\mathrm{Mg}, \mathrm{S}, \mathrm{CaO}, \mathrm{B}, \mathrm{Cu}, \mathrm{Fe}, \mathrm{Mn}, \mathrm{Mo}$ y $\mathrm{Zn}$ $(5 \mathrm{ml} / \mathrm{L})$, repitiendo la dosis al final de la tercera y la cuarta semana de evaluación.

Para el ensayo de enraizamiento in vitro, los datos se analizaron mediante un análisis de varianza ANDEVA de una vía utilizando el programa estadístico de StatSoft, Inc. (2004). STATISTICA (data analyses software system), versión 7.0. Se aplicó un análisis comparativo de las medias de cada promedio utilizando la prueba de Tukey para cada variable con un nivel de confianza del 95.0\%.

Para el ensayo de aclimatación en invernadero se determinó el porcentaje de sobrevivencia de las vitroplantas enraizadas provenientes de cada uno de los tratamientos implementados en el laboratorio.

\section{Resultados y discusión}

\section{Enraizamiento in vitro}

Para la variable longitud de tallo se presentaron diferencias significativas; sin embargo, para la longitud de la raíz y el número de entrenudos no hubo diferencias significativas entre los tratamientos (cuadro I).

La mayor longitud promedio del tallo se obtuvo en TI $(0,125 \mathrm{mg} / \mathrm{L}$ AIB), la cual fue significativamente diferente al resto de los tratamientos, incluyendo el control $(P=0,000)$. Con respecto a la longitud promedio de la raíz, se determinó que a pesar de que no se presentaron diferencias significativas $(P=0,057)$ entre los tratamientos, el Control (T3) fue el que mostró la mayor longitud promedio. Para el número de entrenudos no se presentaron diferencias significativas entre los tratamientos $(P=0,434)$.

Según Sinha (2004), las auxinas controlan el transporte de nutrientes y metabolitos. A mayor concentración de auxinas se conducen más nutrientes y metabolitos que inciden en un mayor 
Cuadro I. Longitud promedio del tallo y de las raíces y el número de entrenudos de las vitroplantas. Centro de Investigación en Biotecnología, Tecnológico de Costa Rica. 2008.

\begin{tabular}{ccccc}
\hline Tratamiento & Concentración mg/LAIB & Media tallo $(\mathrm{cm})^{*}$ & $\begin{array}{c}\text { Media raíz } \\
(\mathbf{c m})^{*}\end{array}$ & $\begin{array}{c}\text { Número de } \\
\text { entrenudos* }\end{array}$ \\
\hline 1 & 0,125 & $6,49 \mathrm{a}$ & $3,72 \mathrm{a}$ & $8 \mathrm{a}$ \\
2 & 0,250 & $5,59 \mathrm{~b}$ & $3,94 \mathrm{a}$ & $8 \mathrm{a}$ \\
3 (Control) & 0,500 & $5,56 \mathrm{~b}$ & $4,73 \mathrm{a}$ & $8 \mathrm{a}$ \\
\hline
\end{tabular}

*Los tratamientos seguidos por la misma letra son estadísticamente iguales según prueba de Tukey al 5\%.

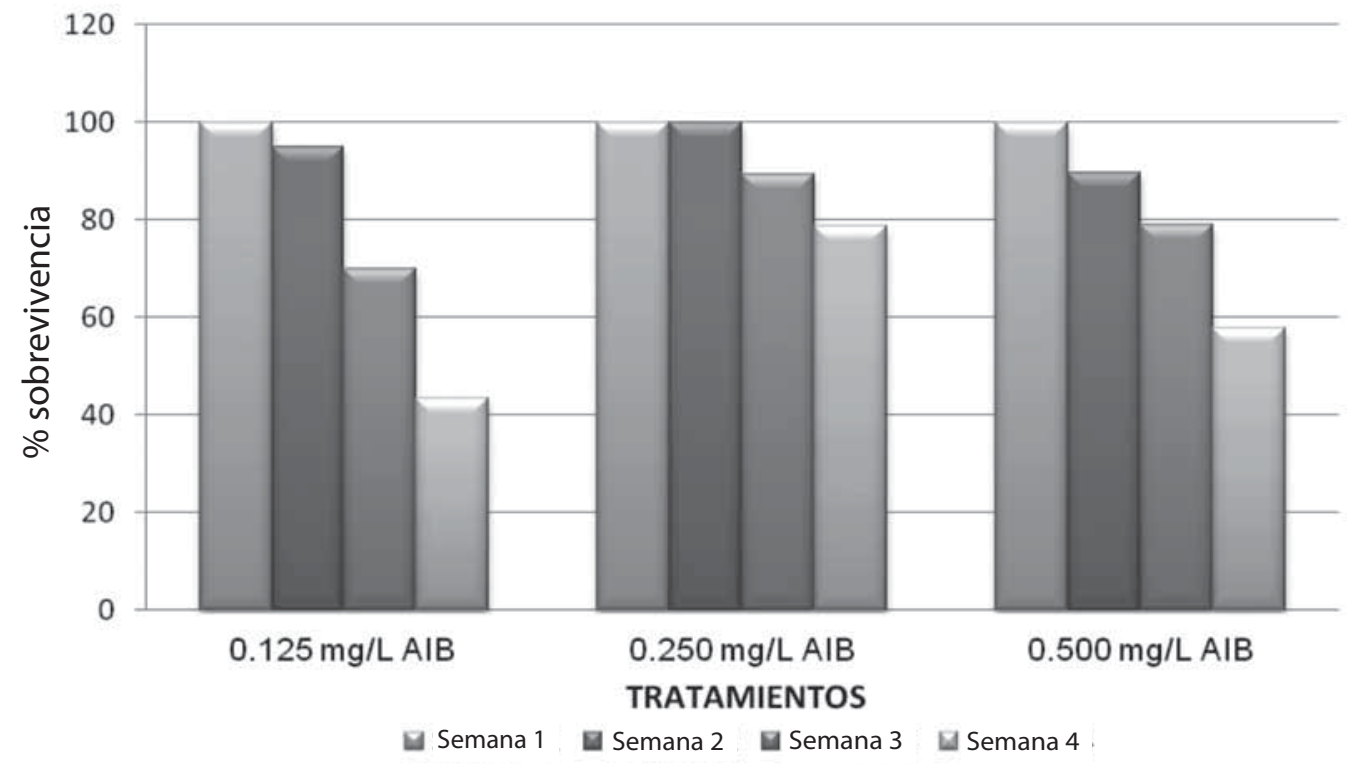

Figura I. Sobrevivencia de vitroplantas de mora en la etapa de aclimatación en invernadero. Centro de Investigación en Biotecnología,Tecnológico de Costa Rica. 2008.

crecimiento, comportamiento observado en todos los tratamientos para la longitud radical promedio. Además, las auxinas favorecen la formación de raíces adventicias y la división celular en tejido dañado, factores que favorecen la aclimatación de la planta.

Aragón y colaboradores (2006) demostraron el efecto que tiene la combinación de auxinas en medios de cultivos líquidos en recipientes automatizados, en el aumento del vigor de los explantes en algunos cultivos tropicales facilitando el manejo posterior del material, ya sea para la producción de brotes de buena calidad en subcultivos, o para la aclimatación directa de las vitroplantas en invernadero.

Se ha comprobado que la reducción de sales al $50 \%$ influye en la inducción de la raíz. Vaario y colaboradores (1995) comprobaron este efecto en Shorea roxburghii donde la disminución de sales del medio al 50\% y la adición de auxinas combinadas AIB + ANA promovieron el enraizamiento hasta en un $50 \%$. La reducción de sales en la composición del medio de cultivo ejerce un estrés fisiológico en las plantas, razón por la cual producen raíces en busca de posibles fuentes de nutrientes físicamente alejadas, con el fin de acelerar el desarrollo radicular (Salisbury y Ross, 1994).

Con el sistema de inmersión temporal se logró disminuir a la mitad el tiempo de enrizamiento, en comparación con el medio semisólido reportado por Flores y colaboradores (2003). La reducción del ciclo in vitro se debe a que los componentes del 

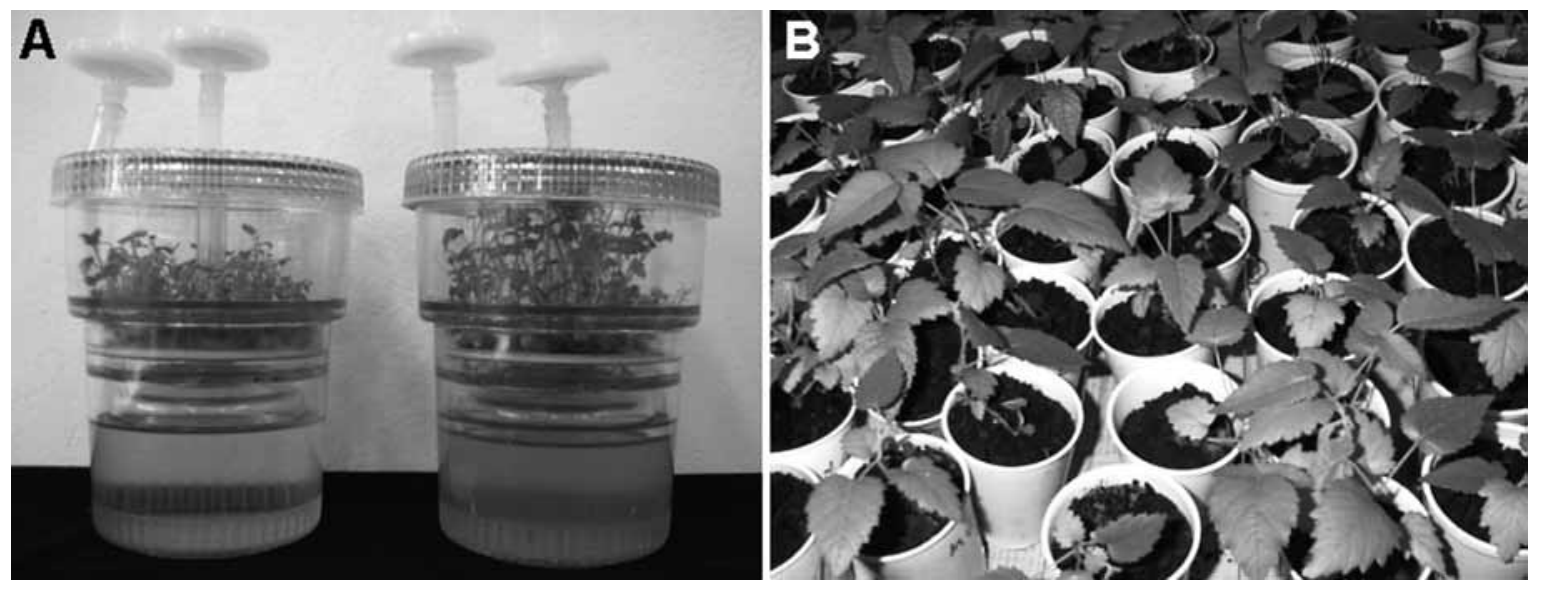

Figura 2. A. Vitroplantas enraizadas empleando el sistema de inmersión temporal. B. Plántulas de mora aclimatadas. Centro de Investigación en Biotecnología, Tecnológico de Costa Rica. 2008.

medio líquido tienen un mayor contacto con el área superficial de la vitroplanta, a diferencia del medio semisólido, en el cual el gelificante da soporte a la planta, pero al mismo tiempo retiene los componentes del medio de cultivo (Smith y Spoomer, 1995).

Además, en los medios líquidos se da una renovación de la atmósfera del sistema, lo que contribuye a la reducción de la hiperhidricidad y la acumulación de gases que pueden interferir en el desarrollo de las plantas (Etienne y Berthouly, 2002). Estudios realizados por Alvard y Teisson (1993) en hibridos de banano mostraron que los sistemas de inmersión temporal incrementan la respuesta de los explantes hasta 3 y 4 veces en comparación con la propagación tradicional en medio semisólido, lo cual contribuye a la aceleración de los periodos de crecimiento.

\section{Invernadero}

Durante la etapa de aclimatación, los promedios de la humedad relativa y la temperatura fueron de $91.8 \%$ $18.3^{\circ} \mathrm{C}$; $74.4 \%-23.2^{\circ} \mathrm{C}$; y $83.8-21.7^{\circ} \mathrm{C} \%$ durante la mañana, el medio día y la tarde, respectivamente.

Las vitroplantas mostraron diferentes porcentajes de sobrevivencia. En todos los tratamientos se observó una disminución de este porcentaje conforme transcurrían las semanas. Se debe resaltar que las vitroplantas provenientes de un crecimiento in vitro con 0,250 mg/L de AIB (T2) lograron el mayor porcentaje de sobrevivencia (78.6\%). Los tratamientos TI y T3 mostraron un $43.3 \%$ y un
57.9\% de sobrevivencia respectivamente, como se muestra en las figuras I y 2 .

Durante la etapa de aclimatación de las plántulas en invernadero, fue vital el control de las condiciones atmosféricas, así como mantener una alta humedad ambiental, temperaturas moderadas, poca luminosidad y protección al viento directo, lo cual contribuyó a disminuir la transpiración de las plántulas, ya que estas poseen una inmadurez en la estructura de la hoja.

En esta etapa, la hoja presenta poca funcionalidad estomática, el mesófilo no está bien diferenciado, tiene poca o nula protección mediante la deposición de ceras cuticulares y la maquinaria fotosintética se encuentra disminuida e influenciada por el bajo número e indiferenciación de los cloroplastos (Pospóšilová et al., 1999). El resultado final de la sobrevivencia evidenció que una vez que las vitroplantas se encuentran fuera de la atmósfera in vitro, son vulnerables a los factores ambientales, reflejándose en la mortalidad obtenida, independiente del tratamiento del que provenían.

La aplicación semanal de polisacáridos de fácil asimilación y microelementos como el Mn, Zn, B facilitaron el endurecimiento y la aclimatación de las plántulas reduciéndoles el estrés en esta etapa (Flores et al., 2005).

Se concluye que conforme se incrementó la concentración de AIB, se obtuvo mayor longitud radical promedio, además las vitroplantas cultivadas en $0.250 \mathrm{mg} / \mathrm{L}$ AIB desarrollaron in vitro una longitud 
de tallo aproximada de $6 \mathrm{~cm}$ y presentaron la mayor sobrevivencia en la etapa de aclimatación.

\section{Agradecimientos}

Los autores agradecen a la Vicerrectoría de Investigación y Extensión del Tecnológico de Costa Rica por la colaboración financiera.

\section{Bibliografía}

Alvard, D; C, Teisson. (1993). Comparation of methods of liquid medium culture for banana micropropagation. Plant Cell Tissue Organ Culture n 32: 55-60.

Aragón, C; Escalona, M; Capote, I; Cejas, I; Rodríguez, R; Sandoval, J; Roels, S; Debergh, P; González-Olmedo, J. (2006). Aspectos metabólicos del crecimiento y desarrollo de plántulas de plátano (CEMSA 3/4) micropropagados en Biorreactores de Inmersión Temporal BIT. Cultivos Tropicales; 27( I): 39-44.

Etienne, H; Berthouly, M. (2002). Temporary immersion system in plant micropropagation. Plant Cell Tissue Organ Culture 69: 215-231.

Flores, D; Jiménez,V; Alpízar, K. (2003). Producción in vitro de plantas de mora y su seguimiento en campo. Memoria. Primer Foro-Taller nacional sobre el cultivo de la mora. Eds. Flores, D; Montero, A; Orozco, R; Argüello, F. 2003. Cartago, Costa Rica, Instituto Tecnológico de Costa Rica: Centro de Información Tecnológica, p.22-33.

Flores, D; Jiménez, V; Ortiz, F. (2005). Micropropagación, enraizamiento y aclimatación de mora (Rubus spp) y su traslado al campo. Cultivo de la Mora. Innovaciones Tecnológicas. Capítulo II. Comp. Flores, D y Argüello, J.F. 2005. Editorial Tecnológica de Costa Rica. Cartago, CR. p.65-75.
Murashige,T; Skoog, F (1962). A revised medium for rapid growth and bioassays with tobacco tissue cultures. Physiol Plant 15(3): 473-497.

Obando, H. (2003). Descripción y evolución del cultivo de la mora en Costa Rica. Foro- Taller Nacional sobre el cultivo de la mora (Rubus spp.) (I: 2003: mayo: San José, Costa Rica). Memoria/. Eds. Flores, D; Montero, A; Orozco, R; Arguello, D. 2003. Cartago, Costa Rica, Instituto Tecnológico de Costa Rica. Centro de Información Tecnológica. p.7l.

Pospóśilová, J; Tichá, l; Kadlecek, P; Haisel, D; Plzáková, S. (1999). Aclimatization of micropropagated plants to ex vitro conditions. Biología Plantarum 42(4): 48 I-497.

Salisbury, F; Roos, C. (1994). Fisiología Vegetal. Parte Tres. Desarrollo Vegetal. Grupo Editorial Iberoamérica S.A. de C.V. México, DF. 363-59I p.

Sinha, R.K. (2004). Modern Plant Physiology. Chapter 19 Hormones/ Growth Regulator. Alpha Science International Ltd. Pangbourne, England. 46I-472 pp.

Smith, M. \& L. Spoomer. (1995). Vessels, gels, liquid media and support systems. pp. 145-163. En: J. AitkenChristie, T. Kozai, M.A.L. Smith (Eds.). Automation and environmental control in plant tissue culture. Kluwer Academic Publishers, Dordrecht, The Netherlands.

StatSoft, Inc.US. (2004). STATISTICA (Data analyses software system) (Programa de Cómputo) Versión 7.0.Tulsa, Oklahoma. I disco compacto, $8 \mathrm{~mm}$. (B).

Taiz, L; Zeiger, E. (2006). Plant Physiology. Chapter 19. Auxin: The Growth Hormone. 4ed. Sinauer Associates. Inc. Sunderland EUA. 440 pp.

Vaario, L.M, Soda, R; Ide, Y. (1995). In vitro plantlet regeneration of Shorea roxburghii G. Don. From axillary of germinated seedlings. J. Jn. For. Soc. 77(3): 263-265.

Wiesman, Z:; Riov, J; Epstein, E. (1989). Characterization and rooting ability of indole-3-butyric acid conjugates formed during rooting of mung bean cuttings. Plant Physiology. n 91: I080- 1084. 